https://doi.org/10.23913/ciba.v9i18.98

Artículos Científicos

\title{
Biomasa de origen vacuno en la remoción de contaminantes básicos en un reactor discontinuo secuencial
}

Biomass of Bovine Origin in the Removal of Basic contaminants in a Sequential Batch Reactor

Biomassa de origem bovina na remoção de contaminantes básicos em reator em batelada sequencial

Carlos Alberto Torres Balcázar

Universidad Juárez Autónoma de Tabasco, División Académica de Ciencias Biológicas,

México

ing_carlos_torres@msn.com https://orcid.org/0000-0001-8011-6721

Gaspar López Ocaña

Universidad Juárez Autónoma de Tabasco, División Académica de Ciencias Biológicas,

México

ocanagl77@hotmail.com https://orcid.org/0000-0002-8402-8160

Mario José Romellón Cerino Instituto Tecnológico de Villahermosa, México mjrcerino@gmail.com https://orcid.org/0000-0002-8579-1280

María Berzabé Vázquez González Instituto Tecnológico de Villahermosa, México marbe_1411@hotmail.com https://orcid.org/0000-0003-2814-8819 
Revista Iberoamericana de las Ciencias Biológicas y Agropecuarias

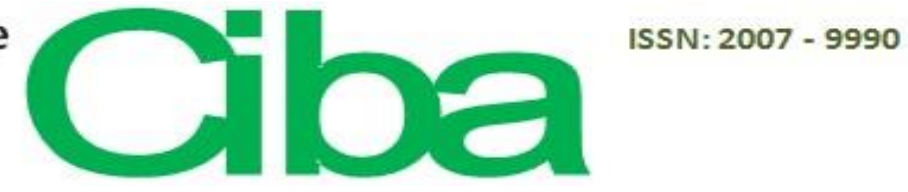

Luis Enrique Comparán Sánchez

Universidad Juárez Autónoma de Tabasco, División Académica de Ciencias Biológicas,

México

luis_com13@hotmail.com

https://orcid.org/0000-0003-3239-342X

\section{Resumen}

El propósito en la presente investigación fue evaluar el potencial del estiércol de ganado vacuno como biomasa en suspensión en reactores discontinuos secuenciales (SBR) a diferentes tiempos de retención hidráulica para mejorar la remoción de contaminantes básicos de agua residual doméstica. Los reactores SBR para el experimento fueron construidos por triplicado con capacidad operativa de $720 \mathrm{~L}$. Al estiércol vacuno a emplear como biomasa en suspensión se le determinó (promedio $\pm D E$ ) la biomasa seca (72.3 \pm $6.2 \%)$, humedad $(27.7 \pm 6.2 \%), \mathrm{pH}(7.8 \pm 1.3)$ y materia volátil $(0.15 \pm 0.05 \mathrm{~kg} \mathrm{mv} / \mathrm{kg}$ estiércol). El lodo microbiano (10 kg de estiércol) se preparó en el SBR con agua residual doméstica estabilizándose en 21 días aproximadamente. Posteriormente, se realizaron experimentos con tiempos de retención hidráulica (TRH) a 15 h, 20 h y 25 h, y se contrastaron con el agua residual cruda. El SBR fue operado con un volumen de lodo activo de $0.29 \mathrm{~m}^{3}$, un volumen de intercambio $0.43 \mathrm{~m}^{3}$ (59.7\%), tiempo de sedimentación de $1 \mathrm{~h}$, tiempo de reacción de 5 h, SSVLM de $1600 \mathrm{mg} / \mathrm{L}$, TMRC de 6 días y Y de $0.21 \mathrm{~kg} / \mathrm{célula} / \mathrm{lb}$. Los datos experimentales de calidad del agua (influente y efluente) fueron analizados estadísticamente con pruebas no paramétricas, al no cumplir postulados de normalidad y homocedasticidad con la prueba de Kruskal-Wallis, y el contraste de medianas de Mann-Whitney con valor $p<$ 0.05 , que indica diferencias estadísticamente significativas entre las medianas con un nivel de $95.0 \%$ de confianza de los tratamientos evaluados. El tratamiento más eficiente fue el TRH $20 \mathrm{~h}$, con (mediana $\pm D E$ ) turbiedad $9.2 \pm 0.84 \mathrm{UNT}$, color con $286.2 \pm 34.53 \mathrm{UC}, \mathrm{pH}$ $6.15 \pm 0.77$, temperatura del agua de $29.9 \pm 1.57^{\circ} \mathrm{C}$, conductividad eléctrica (CE) de 1103.35 $\pm 102.1 \mu \mathrm{S} / \mathrm{cm}$, oxígeno disuelto (OD) con $4.2 \pm 0.42 \mathrm{mg} / \mathrm{L}$, demanda química de oxígeno (DQO) con $35.6 \pm 2.98 \mathrm{mg} / \mathrm{L}$ y sólidos suspendidos totales (SST) de $26.35 \pm 1.20 \mathrm{mg} / \mathrm{L}$. Para el TRH 15 h se obtuvo eficiencias de remoción para DQO de 75.8\%, en el TRH 20 h 92.4\% (DQO); mientras que el TRH $25 \mathrm{~h}$ presentaron eficiencias de 64.5\% (DQO). Esta alternativa de tratamiento cumple con los criterios de descarga a cuerpos receptores establecidos por la NOM-001-SEMARNAT-1996. Los SBR con biomasa vacuna pueden ser empleados con 
Revista Iberoamericana de las Ciencias Biológicas y Agropecuarias

confianza para pequeños caudales discontinuos, ya que no utiliza equipos sofisticados, no requiere reactivos dañinos secundarios y su único requerimiento es la energía eléctrica.

Palabras clave: demanda química de oxígeno, eficiencia de remoción, estiércol, tiempo de retención hidráulica.

\section{Abstract}

The purpose of the present investigation was to evaluate the potential of cattle manure as biomass in suspension in sequential discontinuous reactors (SBR) at different hydraulic retention times, to improve the removal of basic contaminants from domestic wastewater. The SBR reactors for the experiment were built in triplicate with an operating capacity of $720 \mathrm{~L}$. The bovine manure to be used as biomass in suspension was determined (average \pm SD) the dry biomass $(72.3 \pm 6.2 \%)$, humidity $(27.7 \pm 6.2 \%), \mathrm{pH}(7.8 \pm 1.3)$ and volatile matter $(0.15 \pm 0.05 \mathrm{~kg} \mathrm{mv} / \mathrm{kg}$ manure). The microbial sludge (10 kg of manure) was prepared in the SBR with domestic residual water, stabilizing in approximately 21 days, subsequently experiments with hydraulic retention times (TRH) were performed at 15, 20 and 25 hours, contrasting with the residual water raw. The SBR was operated with an active mud volume of $0.29 \mathrm{~m}^{3}$, an exchange volume of $0.43 \mathrm{~m}^{3}(59.7 \%)$, settling time of $1 \mathrm{~h}$, reaction time of 5 h, SSVLM of $1600 \mathrm{mg} / \mathrm{L}$, TMRC of 6 days and Y of $0.21 \mathrm{~kg} /$ cell / lb. The experimental data on water quality (influent and effluent) were statistically analyzed with non-parametric tests, as they did not meet normality and homoscedasticity postulates with the Kruskal-Wallis test and the Mann-Whitney test of medians with a P-value <0.05, indicating statistically significant differences between the medians with a level of $95.0 \%$ confidence of the evaluated treatments. The most efficient treatment was HRT $20 \mathrm{~h}$, with (median \pm SD) Turbidity 9.2 \pm 0.84 UNT, Color with $286.2 \pm 34.53$ UC, pH $6.15 \pm 0.77$, water temperature of $29.9 \pm 1.57^{\circ} \mathrm{C}$, Electrical conductivity (EC) of $1103.35 \pm 102.1 \mu \mathrm{S} \mathrm{cm}^{-1}$, dissolved oxygen (DO) with $4.2 \pm 0.42 \mathrm{mg} / \mathrm{L}$, chemical oxygen demand (COD) with $35.6 \pm 2.98 \mathrm{mg} / \mathrm{L}$ and total suspended solids (TSS) of $26.35 \pm 1.20 \mathrm{mg} / \mathrm{L}$, For the 15-hour HRT, removal efficiencies for COD of $75.8 \%$ were obtained, in the 20-hour HRT 92.4\% (COD); while the 25-hour HRT presented efficiencies of $64.5 \%$ (COD). This treatment alternative meets the criteria for discharge to receptor bodies established by NOM-001-SEMARNAT-1996. SBRs with vaccine biomass can be used with confidence for small discontinuous flows, since they 
Revista Iberoamericana de las Ciencias Biológicas y Agropecuarias

do not use sophisticated equipment, do not require secondary harmful reagents and their only requirement is electrical energy.

Keywords: chemical oxygen demand, removal efficiency, manure, hydraulic retention time.

\section{Resumo}

O objetivo da presente investigação foi avaliar o potencial do esterco bovino como biomassa suspensa em reatores sequenciais em batelada (SBR) em diferentes tempos de retenção hidráulica para melhorar a remoção de contaminantes básicos de águas residuais domésticas. Os reatores SBR para o experimento foram construídos em triplicata com capacidade operacional de 720 L. O esterco bovino a ser utilizado como biomassa suspensa foi determinada (média \pm DP) a biomassa seca $(72,3 \pm 6,2 \%)$, umidade $(27,7 \pm 6,2 \%), \mathrm{pH}(7,8$ $\pm 1,3)$ e matéria volátil $(0,15 \pm 0,05 \mathrm{~kg} \mathrm{mv} / \mathrm{kg}$ de esterco $)$. O lodo microbiano (10 $\mathrm{kg}$ de esterco) foi preparado no SBR com esgoto doméstico, estabilizando em aproximadamente 21 dias. Posteriormente, foram realizados experimentos com tempos de retenção hidráulica (TRH) às $15 \mathrm{~h}, 20 \mathrm{~h}$ e $25 \mathrm{~h}$, e contrastados com água residuária bruta. O SBR foi operado com volume de lodo ativo de $0,29 \mathrm{~m}^{3}$, volume de troca de $0,43 \mathrm{~m}^{3}(59,7 \%)$, tempo de sedimentação de 1 h, tempo de reação de 5 h, SSVLM de 1600 mg/L, TMRC de 6 dias e Y de $0,21 \mathrm{~kg} /$ célula / $\mathrm{lb}$. Os dados experimentais de qualidade da água (afluente e efluente) foram analisados estatisticamente com testes não paramétricos, pois não atenderam aos postulados de normalidade e homocedasticidade com o teste de Kruskal-Wallis, e as medianas de Mann-Whitney contrastam com $\mathrm{p}<0,05$, o que indica diferenças estatisticamente significativas entre as medianas com nível de confiança de 95,0\% dos tratamentos avaliados. O tratamento mais eficiente foi TRH $20 \mathrm{~h}$, com (mediana \pm DP) turbidez 9,2 \pm 0,84 NTU, cor com 286,2 $\pm 34,53 \mathrm{UC}, \mathrm{pH}$ 6,15 $\pm 0,77$, temperatura da água de $29,9 \pm 1,57{ }^{\circ} \mathrm{C}$, condutividade elétrica (CE) de 1103,35 $\pm 102,1 \mu \mathrm{S} / \mathrm{cm}$, oxigênio dissolvido (DO) com 4,2 \pm 0,42 mg/L, demanda química de oxigênio (DQO) com 35,6 \pm 2,98 mg/L e sólidos suspensos totais (SST) de 26,35 \pm 1,20 mg/L. Para as $15 \mathrm{~h}$ TRH foram obtidas eficiências de remoção para DQO de 75,8\%, no TRH de 20 h 92,4\% (DQO); enquanto o TRH 25 h apresentou eficiências de 64,5\% (COD). Esta alternativa de tratamento atende aos critérios de descarga para órgãos receptores estabelecidos pela NOM-001SEMARNAT-1996. Os SBRs com biomassa bovina podem ser usados com segurança para 
pequenos fluxos descontínuos, uma vez que não utiliza equipamentos sofisticados, não requer reagentes secundários nocivos e sua única exigência é a energia elétrica.

Palavras-chave: demanda química de oxigênio, eficiência de remoção, esterco, tempo de retenção hidráulica.

Fecha recepción: Enero 2020

Fecha aceptación: Julio 2020

\section{Introducción}

Las comunidades urbanas y rurales, en busca del crecimiento económico, han multiplicado el consumo de materiales y, por extensión, han aumentado la generación de desechos. Esto ha traído como consecuencia la contaminación del agua: la han modificado física, química y biológicamente, lo que ha generado un desequilibrio que afecta tanto a la productividad de los sistemas como a la salud humana. (Ghizellaoui y Ghizellaoui, 2010).

El proceso de lodos activados como tratamiento de aguas residuales fue desarrollado en Manchester, Inglaterra, en 1914. Para 1920, varias plantas iniciaban su operación en Estados Unidos de Norteamérica, sin embargo, el uso extensivo de este sistema se dio hasta 1940. Los primeros investigadores notaron que la cantidad de materia biodegradable que entraba al sistema afectaba la tasa del metabolismo. Los diseños en esa época fueron totalmente empíricos y el tiempo de retención hidráulica (TRH) del tanque de aeración fue uno de los primeros parámetros de diseño. Por lo general se seleccionaban cortos tiempos de retención para cargas orgánicas bajas y tiempos de retención prolongados para cargas orgánicas altas. Posteriormente, surgieron criterios relacionados con la carga orgánica y los microorganismos del sistema, y se llegó a la relación hoy conocida como alimento/microorganismo (A/M) (Comisión Nacional del Agua [Conagua], 2016).

El reactor secuencial por tandas (SBR, por sus siglas en inglés) es un sistema de lodos activados para el tratamiento de aguas residuales (domésticas e industriales) que utiliza ciclos de llenado y descarga. En un reactor es necesario garantizar un nivel de oxígeno en el tanque de aireación mínimo de $2 \mathrm{mg} / \mathrm{L}$ y máximo de $4 \mathrm{mg} / \mathrm{L}$. El nivel de sólidos suspendidos en el licor mezclado a nivel bajo de agua debe mantenerse alrededor de $4000 \mathrm{mg} / \mathrm{L}$ para aguas residuales domésticas, con el propósito de proveer condiciones de inanición en el tanque de aireación con las cuales pueda obtenerse un lodo de purga estabilizado. El tratamiento del ciclo va de 4 h a 24 h, con una relación A/M de 0.15-0.6 días ${ }^{-1}$. Comparado con otros sistemas aerobios, el SBR presenta una alta producción de biomasa, tiene poca capacidad de reducción 
Revista Iberoamericana de las Ciencias Biológicas y Agropecuarias

en la aireación y requiere una alta atención por parte del operador (Environmental Protection Agency [EPA], 1999).

Al respecto, Li, Healy, Zhan y Rodgers (2008) evaluaron el rendimiento de un SBR de $10 \mathrm{~L}$ de volumen en el tratamiento de aguas residuales de matadero. El agua residual presentó un afluente con $4672 \pm 952 \mathrm{mg} / \mathrm{L}$ de demanda química de oxígeno (DQO), $356 \pm$ $46 \mathrm{mg} / \mathrm{L}$ de nitrógeno total (NT) y $29 \pm 10 \mathrm{mg} / \mathrm{L}$ de fósforo total (PT). El ciclo completo fue de ocho horas y estuvo conformado de cuatro fases: llenado (7 min), reacción (393 min), sedimentación (30 min) y vaciado/inactivo (50 min). Durante la fase de reacción, el reactor se aireó intermitentemente con un suministro de aire de $0.8 \mathrm{~L} / \mathrm{min}$ cuatro veces a intervalos de 50 min. A una tasa de carga orgánica del afluente de $1.2 \mathrm{~g} \mathrm{DQO} \mathrm{L}^{-1} \mathrm{~d}^{-1}$, las concentraciones

promedio de efluentes de DQO, NT y PT fueron $150 \mathrm{mg} / \mathrm{L}, 15 \mathrm{mg} / \mathrm{L}$ y $0.8 \mathrm{mg} / \mathrm{L}$, respectivamente. Esto representó para la DQO, NT y PT una remoción de 96 \%, 96 \% y 99 \%, respectivamente. Las fases mostraron que la absorción biológica de fósforo se produjo en el primer periodo de aireación y la remoción del nitrógeno se llevó a cabo en el siguiente tiempo de reacción, por medio de la nitrificación y desnitrificación parcial. El análisis del balance de nitrógeno indicó que la desnitrificación y la síntesis de biomasa contribuyeron en $66 \%$ y 34\% a la eliminación del NT, respectivamente (Li et al., 2008).

Otro estudio, el de Pire, Palmero, Araujo y Díaz (2010), evaluó la eficiencia de un SBR en la remoción de materia orgánica, nutrientes y metales pesados utilizando una mezcla de dos fracciones de vertidos de una tenería. Los autores compararon las eficiencias de remoción obtenidas al alimentar el reactor con afluentes diluidos y concentrados, variando el TRH en 8 y 12 horas. Durante el tiempo de reacción se combinaron fases anóxicas y óxicas. Se obtuvo que la remoción de contaminantes fue estadísticamente mayor cuando se usaron afluentes diluidos (DQO $1000 \mathrm{mg} / \mathrm{L}$ y $\left.\left[\mathrm{Cr}^{3+}\right] £ 10 \mathrm{mg} / \mathrm{L}\right)$, independientemente del TRH utilizado: la mayor eliminación se logró durante la fase anóxica. Las remociones no mostraron diferencia estadística entre ellas, oscilando para los tratamientos con afluentes diluidos entre $82.5 \%$ y $84.2 \%$ para la DQO; $58.0 \%$ y $73.9 \%$ para $\mathrm{P}_{-} \mathrm{PO}_{4}{ }^{3-}$ y $51.2 \%$ y $53.9 \%$ para el Cr. La eliminación de N se realizó por asimilación debido a que los microorganismos nitrificantes fueron más sensibles e inhibieron su actividad frente a la presencia del cromo y altas concentraciones de materia orgánica. La remoción de cromo se logró por precipitación o adsorción en el lodo, por lo que fue fundamental controlar el $\mathrm{pH}$ en los reactores entre 7.5 y 8.5 unidades (Pire et al., 2010). 
El objetivo del tratamiento de aguas residuales es la remoción de sustancias contaminantes a fin de evitar efectos negativos en los ecosistemas acuáticos y lograr que la calidad del agua sea la adecuada de acuerdo con sus usos potenciales o vertido en cuerpos receptores (Secretaría de Medio Ambiente y Recursos Naturales [Semarnat]-Conagua, s. f.). En México, las plantas de tratamiento de lodos activados y sus variantes, entre ellos el SBR, son 746 , lo que representa $30.12 \%$ de las plantas de tratamiento instaladas en el país; cuentan una capacidad instalada de tratamiento de $94485.8 \mathrm{~L} / \mathrm{s}(53.09 \%)$ y una capacidad de operación de 67 059.7 L/s $(55.47 \%$ ) de aguas residuales generadas en el país (Conagua, 2015). Estas plantas han tenido paros y bajas eficiencias de remoción tanto en materia orgánica como nutrientes, pues presentan descontroles de proceso (variaciones de $\mathrm{pH}$, temperatura, carga y caudal) y pierden el cultivo suspendido, siendo estos responsables de la degradación de materia orgánica y demás contaminantes. Para formar nuevamente el cultivo, estos sistemas pueden tardar hasta seis meses en estabilizarse y establecer una eficiencia de remoción buena.

La diferencia principal entre un reactor de flujo continuo y otro de flujo discontinuo radica en que en el primero el proceso se desarrolla en una secuencia espacial, mientras que en el segundo el proceso se desarrolla en una secuencia temporal (Nájera, 2012). Una de las ventajas más importantes de los reactores discontinuos secuenciales es que todas las operaciones y procesos unitarios se desarrollan dentro del mismo tanque de reacción, lo que significa un ahorro económico sustancial en los costos de capital al no haber necesidad de clarificadores y otros equipos adicionales (Noyola, Morgan y Güereca, 2013). Dado que la decantación ocurre en el mismo tanque de reacción, se reduce de manera significativa la pérdida de lodos, lo que permite tener un mejor control en la concentración de los lodos activados. Por lo anterior expuesto, en este estudio se evalúa el potencial del uso de estiércol de ganado vacuno en la formación de biomasa en suspensión para un SBR en la remoción de contaminantes básicos bajo diversos tiempos de retención hidráulica. Con esta información se genera un procedimiento para la generación de biomasa activa en este tipo de reactores que permite optimizar los tiempos y la remoción de contaminantes con materia prima disponible a bajo costo. 


\section{Materiales y método}

El sistema experimental SBR fue construido en la División Académica de Ciencias Biológicas (DACBiol) de la Universidad Juárez Autónoma de Tabasco (UJAT) (N 17 59` $26^{\prime \prime}$ y $17^{\circ} 59^{\prime} 17^{\prime \prime}$; W 58 $16^{\prime \prime}$ y $\left.92^{\circ} 58^{\prime} 37^{\prime \prime}\right)$. El agua residual para tratar provino del cárcamo concentrador de las instalaciones sanitarias de ese espacio. El estiércol bovino para la formación de biomasa activa fue colectado en campos ganaderos $\left(17^{\circ} 57^{\prime} 06.24^{\prime \prime} \mathrm{N}\right.$ y $92^{\circ} 57^{\prime}$ 18.47" O), del municipio de Centro, Tabasco. Los parámetros de calidad del agua de los experimentos se determinaron en el Laboratorio de Tecnología del Agua de dicha institución.

\section{Características del SBR}

Los reactores SBR fueron diseñados y construidos bajo criterios establecidos por la EPA (1999), Crites y Tchobanoglous (2000), Araya, Vera, Morales, López y Vidal (2014) y la Conagua (2016). Estos cuentan con dimensiones de $0.9 \mathrm{~m}$ de largo x $0.9 \mathrm{~m}$ de ancho x 1.1 $\mathrm{m}$ de alto. Fueron construidos con recipientes comerciales de plástico y protección de aluminio, con capacidad de 1000 L, pero fueron operados con un volumen de 720 L. En la parte interna se instaló un sistema de difusión de aire suministrado con un equipo Blower cuya potencia era de un caballo de fuerza (HP). El suministro de agua era del cárcamo receptor de aguas residuales sanitarias mediante una bomba de 1/4 de HP. La pailería interna consiste de accesorios y tuberías hidráulicas de policloruro de vinilo (PVC) de una pulgada, como válvulas, codos, T, conectores, etc. Para la dispersión del oxígeno, se instalaron tuberías con orificios de $0.2 \mathrm{~cm}$ de diámetros. Estos difusores fijos en el fondo del tanque tienen la capacidad de inyectar el aire generando burbujas finas que promueven una mejor oxigenación del agua (figura 1). Dentro del SBR se realizaron todas las etapas, es decir, se llevó a cabo la preparación del lodo microbiano, el tratamiento de agua residual (por lotes), la clarificación o decantación del agua tratada. Se reusaron los lodos activados (en el mismo reactor), a fin de mantener la concentración adecuada de lodos activados para posteriores tratamientos. El SBR contó con entrada de agua residual cruda por bombeo, una salida para los lodos en el fondo de la cámara y una salida para la extracción del agua tratada y clarificada (figura 2). 
Figura 1. Arreglo del reactor discontinuo secuencial y complementos auxiliares
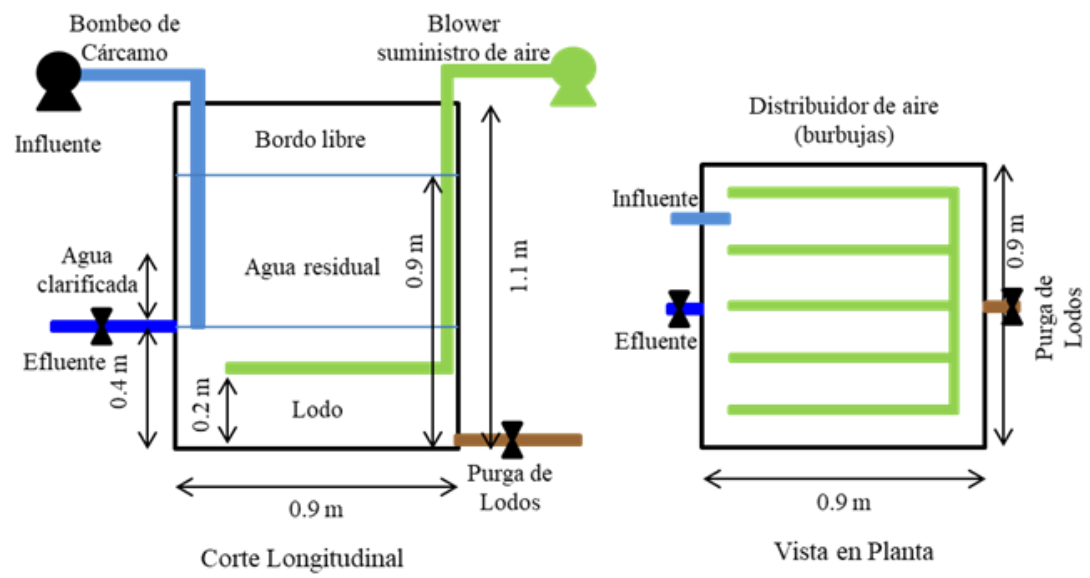

Fuente: Elaboración propia

Figura 2. Fases de funcionamiento del sistema SBR; un solo tanque lleva a cabo las funciones de igualación, aireación y sedimentación en una secuencia de tiempo

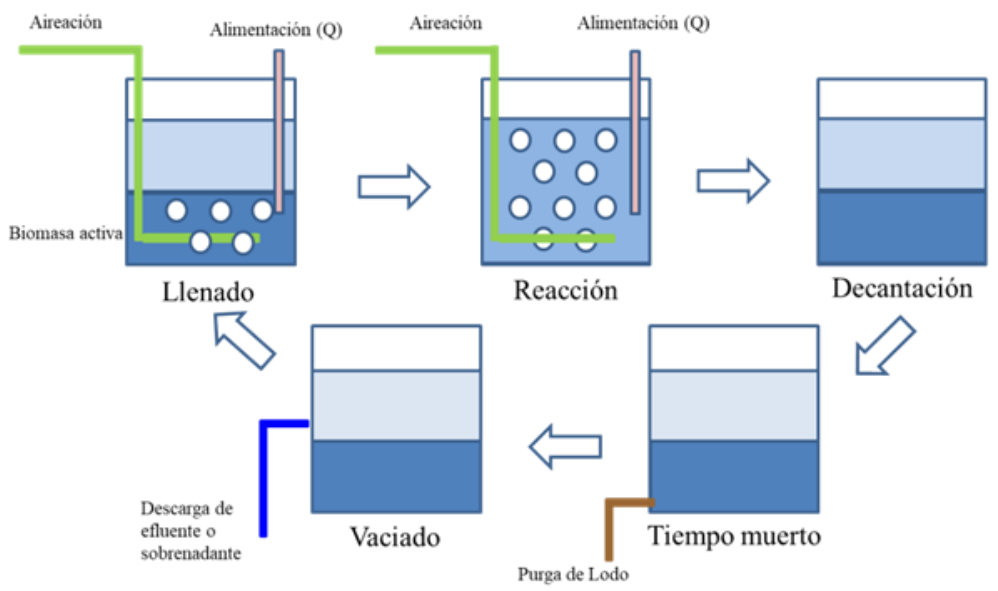

Fuente: Elaboración propia

\section{Preparación del lodo microbiano}

El inóculo (cultivo de microorganismos) se generó a partir de la materia fecal de ganado vacuno. Este estiércol, una vez recolectado en campo, se le determinó humedad, pH y sólidos volátiles. Posteriormente, en el SBR se añadió $10 \mathrm{~kg}$ de estiércol hasta aforar 290 L de agua residual, lo que formó una mezcla de entre 2000 y 3000 mg/L de sólidos en suspensión volátiles en el licor mezcla (SSVLM) (Levin y Gealt, 1997; Méndez, Miyashiro, Rojas, Cotrado y Carrasco, 2004). El cultivo se mantuvo en aclimatación durante 21 días antes de los experimentos. Se inició con la aireación manteniendo cinco días estabilizándolos. 
Durante este periodo se monitorearon parámetros como $\mathrm{pH}$, turbiedad, color, temperatura y oxígeno disuelto (OD). Después de los cinco días, se efectuó la purga de lodos; el vaciado del agua se realizó una vez al día durante 16 días hasta finalizar el proceso de estabilización (Conagua, 2016). En los SBR la concentración máxima de entrada (Co) se estimó alrededor de $600 \mathrm{mg} / \mathrm{L}$ de DQO y la de salida $(\mathrm{Ct})$ menor a $30 \mathrm{mg} / \mathrm{L}$. El agua residual presentó un orden de reacción igual a uno $(n=1)$ (Crites y Tchobanoglous, 2000). Los TRH del SBR, para este estudio, se establecieron a 15, 20 y 25 horas. Después de la estabilización, el reactor se alimentó hasta un volumen de 720 L y se arrancó el experimento. A continuación, en la tabla 1, se presentan las características de operación del sistema.

Tabla 1. Parámetros de operación del SBR en la fase experimental.

\begin{tabular}{|l|c|c|}
\hline \multicolumn{1}{|c|}{ Parámetro } & Valor & Unidad \\
\hline Q entrada & 0.0875 & $\mathrm{~m}^{3} / \mathrm{h}$ \\
\hline Núm. de tanques (réplicas) & 3 & \\
\hline TRH & $15-20-25$ & $\mathrm{~h}$ \\
\hline DQO soluble & 460.0 & $\mathrm{mg} / \mathrm{L}$ \\
\hline Correlación DBO 5-DQO & 0.6 & \\
\hline Vol. operación & 0.72 & $\mathrm{~m}^{3}$ \\
\hline Vol. de Lodos & 0.29 & $\mathrm{~m}^{3}$ \\
\hline Vol. de intercambio & 0.43 & $\mathrm{~m}^{3}$ \\
\hline$\%$ Intercambio & 59.7 & \\
\hline Tiempo de llenado & 10 & $\mathrm{Min}$ \\
\hline Tiempo de ciclo & 30 & $\mathrm{Min}$ \\
\hline Tiempo de sedimentación & 1 & $\mathrm{~h}$ \\
\hline Tiempo de decantación & 1 & $\mathrm{~h}$ \\
\hline Tiempo muerto & 1 & $\mathrm{~h}$ \\
\hline Tiempo de reacción & 5 & $\mathrm{~h}$ \\
\hline SSLM & 2,000 & $\mathrm{mg} / \mathrm{L}$ \\
\hline SSVLM & 1600 & $\mathrm{mg} / \mathrm{L}$ \\
\hline TMRC (Oc) & 6 & días \\
\hline Y = sustrato (DQO) consumidos & 0.21 & $\mathrm{~kg} / \mathrm{célula} / \mathrm{lb}^{-1}$ \\
\hline Kd & 0.06 & Días \\
\hline Sólidos efluentes biodegradables & 80.0 & $\%$ \\
\hline
\end{tabular}

Fuente: Elaboración propia 


\section{Parámetros de calidad del agua}

Los parámetros de calidad del agua analizados durante la evaluación fueron temperatura, turbiedad, color, $\mathrm{pH}, \mathrm{CE}, \mathrm{OD}$, sólidos suspendidos totales (SST) y DQO. Estos se midieron al inicio y final en cada uno de los experimentos, tomando como muestra de entrada el agua residual cruda (influente) obtenida del cárcamo concentrador, la cual fue denominada TRH $O \mathrm{~h}$, y como muestra de salida (efluente) la obtenida después de cada experimento diferente, TRH 15 h, 20 h y 25 h. Los métodos usados para la medición de los parámetros fueron los siguientes: la temperatura (2550 Temperature, 2017), la CE (2510 Conductivity, 2017) y el pH (4500-H+ pH Value, 2017) fueron medidos con el equipo Hanna HI98129. La turbiedad se determinó por el método EPA 180.1, TC-300e, ISO7027, TC-300i, utilizando el equipo Hanna HI 98703 con una precisión de 0.01 UNT. El color se determinó mediante el estándar 2120 Color (2017), con el equipo Lamotte y con una precisión de 0.1 UC. El OD se determinó por el estándar 4500-H+ pH Value (2017). La DQO por el método de la EPA 410.4 (O'Dell, 1993). Los SST se determinaron por la norma NMX-AA-034-SCFI2001 (Secretaría de Economía, s. f.). En la fase experimental con los SBR, se midieron los parámetros de control y contaminantes básicos en el periodo agosto-diciembre 2018. Cada experimento ( $15 \mathrm{~h}, 20 \mathrm{~h}$ y $25 \mathrm{~h}$ ) se realizó seis veces por triplicado (con sus respectivas réplicas), midiendo influente y efluente. De acuerdo con la campaña de muestreo, se obtuvieron 36 muestras por experimento (tratamiento y dos réplicas); un total de 108 muestras fueron analizadas para los tres tratamientos.

\section{Eficiencia de remoción}

Las eficiencias de remoción fueron calculadas con la ecuación siguiente:

$$
E R(\%)=\left(\frac{C E-C S}{C E}\right) X 100
$$

Donde $E R$ es el porcentaje de eficiencia de remoción, $C E$ es la concentración de entrada, $C S$ es la concentración obtenida a la salida del SBR; fue aplicada a cada contaminante o parámetro (Vázquez y López, 2011). 


\section{Diseño experimental y análisis estadístico}

Fue requerido usar un diseño aleatorio de un factor para llevar a cabo el análisis de los sistemas de tratamiento (TRH) y sus controles (agua residual cruda). Para cada uno de estos se corrió por triplicado (agosto-diciembre del 2018). Los parámetros analizados no presentaron un comportamiento normal y homocedástico, por lo que se les determinó un análisis no paramétrico mediante la prueba de Kruskal-Wallis y contraste de medianas de Mann-Whitney. Para establecer la existencia de una diferencia estadísticamente significativa entre las medianas, se estableció el valor $p<0.05$. Finalmente, para desarrollar las pruebas estadísticas, se utilizó el paquete estadístico Statgraphics 16.

\section{Resultados}

\section{Características del estiércol de origen vacuno}

Las características iniciales del estiércol de origen vacuno antes de ser utilizado para generar la biomasa en suspensión en el SBR se presentan en la tabla 2.

Tabla 2. Parámetros físicos del estiércol de origen vacuno. Valores promedio y desviación estándar (DE) $(N=12)$.

\begin{tabular}{|l|c|c|c|}
\hline \multicolumn{1}{|c|}{ Parámetro } & $\boldsymbol{X}$ & $\mathbf{\pm} \boldsymbol{E}$ & Unidad \\
\hline Biomasa seca & 72.3 & 6.2 & $\%$ \\
\hline Biomasa húmeda & 27.7 & 6.2 & $\%$ \\
\hline $\mathrm{pH}$ & 7.8 & 1.3 & $\mathrm{UpH}$ \\
\hline Materia volátil & 0.15 & 0.05 & $\begin{array}{c}\mathrm{kg} \mathrm{Mv} / \mathrm{kg} \\
\text { estiércol }\end{array}$ \\
\hline
\end{tabular}

Fuente: Elaboración propia

\section{Evaluación de parámetros de control y contaminantes básicos}

Los contaminantes básicos y parámetros de control del agua de entrada a los SBR se presentan en la tabla 3. Es importante ver que las características del agua residual a tratar caen dentro de la categoría de media según la concentración de SST $\left(220 \mathrm{mg} / \mathrm{L}^{-1}\right)$, y en el caso de la DQO, está en el rango media-débil (250-500 mg/ $\left./ \mathrm{L}^{-1}\right)$, según lo establece Tchobanoglous, Burton y Stensel (2003). 
Tabla 3. Parámetros de control y contaminantes básicos del agua residual de entrada a los SBR. Valores promedio y desviación estándar $(N=18)$.

\begin{tabular}{|l|c|c|}
\hline Parámetro & $\boldsymbol{X}$ & $\mathbf{\pm D E}$ \\
\hline Turbiedad (UNT) & 85.0 & 29.7 \\
\hline Color $(\mathrm{UC})$ & 986.0 & 132.9 \\
\hline $\mathrm{pH}$ & 8.2 & 0.9 \\
\hline Temperatura $\left({ }^{\circ} \mathrm{C}\right)$ & 28.2 & 1.2 \\
\hline CE $(\mu \mathrm{s} / \mathrm{cm})$ & 1480.1 & 205.5 \\
\hline OD $(\mathrm{mg} / \mathrm{L})$ & 0.5 & 0.2 \\
\hline DQO $(\mathrm{mg} / \mathrm{L})$ & 320.0 & 119.6 \\
\hline SST $(\mathrm{mg} / \mathrm{L})$ & 227.1 & 83.5 \\
\hline
\end{tabular}

Fuente: Elaboración propia

En la tabla 4 se presentan los resultados promedio ( \pm DE) de los influentes y efluentes en los diferentes tratamientos en los SBR. Los parámetros analizados como DQO y SST muestran que el agua residual de entrada en los tres tratamientos es de característica de agua residual media (Tchobanoglous et al., 2003). Aunque estos presentan variabilidad de carga en la fuente de abastecimiento como cualquier sistema generador de agua residual doméstica.

Tabla 4. Comparación de parámetros de control y contaminantes básicos del agua residual a la entrada y salida de los SBR en cada tratamiento. Valores promedio y DE $(N=18)$

\begin{tabular}{|c|c|c|c|c|c|c|c|c|c|c|c|c|}
\hline \multirow[t]{2}{*}{ Parámetro } & \multicolumn{4}{|c|}{ TRH $15 \mathrm{~h}$} & \multicolumn{4}{|c|}{ TRH $20 \mathrm{~h}$} & \multicolumn{4}{|c|}{ TRH $25 \mathrm{~h}$} \\
\hline & Inf. & $\pm D E$ & Efl. & $\pm D E$ & Inf. & $\pm D E$ & Efl. & $\pm D E$ & Inf. & $\pm D E$ & Efl. & $\pm D E$ \\
\hline Turb. (UNT) & 68.6 & 15.2 & 16.6 & 3.9 & 121.5 & 10.0 & 9.6 & 0.8 & 62.8 & 5.2 & 21.3 & 3.4 \\
\hline Color (UC) & 1063.5 & 123.2 & 426.5 & 79.3 & 1014.3 & 101.0 & 291.4 & 34.5 & 870.3 & 87.4 & 442.2 & 102.0 \\
\hline $\mathrm{pH}$ & 7.5 & 0.3 & 6.1 & 0.3 & 9.3 & 0.1 & 6.4 & 0.8 & 7.7 & 0.2 & 6.2 & 0.2 \\
\hline Temp. $\left({ }^{\circ} \mathrm{C}\right)$ & 29.0 & 1.3 & 29.0 & 1.7 & 28.0 & 0.9 & 29.7 & 1.6 & 27.3 & 0.8 & 28.5 & 0.7 \\
\hline $\mathrm{CE}(\mu \mathrm{s} / \mathrm{cm})$ & 1304.7 & 232.7 & 964.5 & 102.5 & 1659.0 & 19.1 & 1075.2 & 102.1 & 1467.7 & 75.6 & 986.5 & 40.6 \\
\hline OD $(\mathrm{mg} / \mathrm{L})$ & 0.6 & 0.1 & 3.2 & 0.6 & 0.3 & 0.1 & 4.3 & 0.4 & 0.6 & 0.1 & 3.9 & 0.1 \\
\hline DQO $(\mathrm{mg} / \mathrm{L})$ & 259.4 & 57.4 & 62.9 & 14.5 & 465.9 & 37.7 & 35.4 & 3.0 & 226.7 & 33.0 & 80.4 & 12.9 \\
\hline SST (mg/L) & 185.3 & 41.0 & 44.9 & 10.4 & 328.5 & 27.9 & 26.1 & 1.2 & 161.9 & 23.6 & 57.4 & 9.2 \\
\hline
\end{tabular}




\section{Turbiedad}

La prueba de Kruskal-Wallis evaluó la hipótesis de que las medianas de turbiedad (UNT) dentro de cada uno de los cuatro niveles de tratamientos sean iguales; encontró que existe una diferencia estadísticamente significativa entre las medianas. Entre los tratamientos, el que presentó la menor mediana $\pm D E$ es el tratamiento TRH $20 \mathrm{~h}$ con $9.2 \pm$ 0.84 UNT, seguido de TRH 15 h con $16.9 \pm 3.86$ UNT y TRH 25 con $20.65 \pm 3.41$ UNT. El TRH $0 \mathrm{~h}$ presentó el valor más alto de media con $72.65 \pm 29.02$ UNT. Cabe recordar que esta última es el agua de entrada (figura 3).

Figura 3. Valores de turbiedad en cada tratamiento. Contraste de medianas (mediana \pm RI)

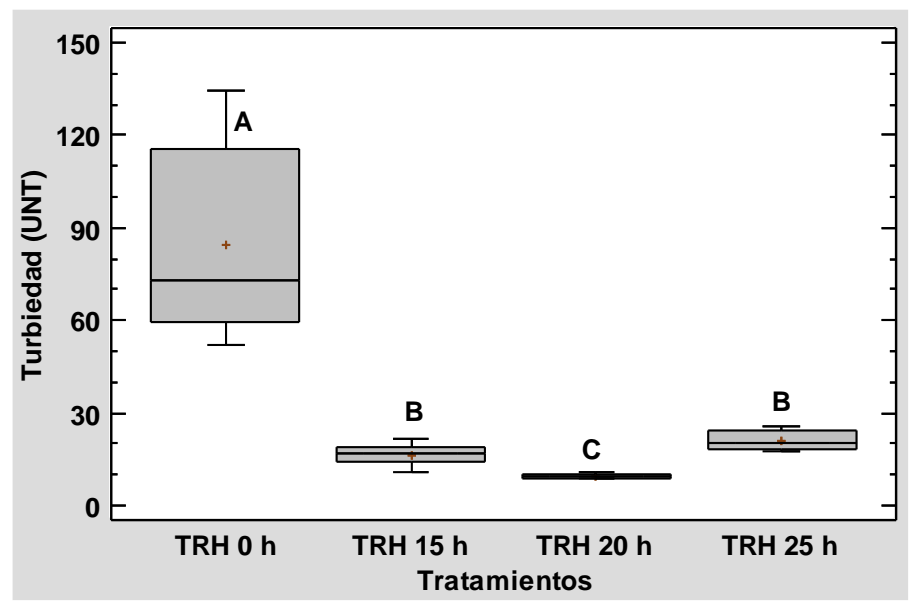

Nota: El tamaño de muestras compuestas es $N=18$ para cada tratamiento. Letras diferentes representan diferencias estadísticamente significativas

Fuente: Elaboración propia

\section{Color}

La prueba de Kruskal-Wallis para color (UC) muestra que existe una diferencia estadísticamente significativa entre las medianas. El tratamiento con el menor valor de mediana \pm DE fue TRH $20 \mathrm{~h}$ con $286.2 \pm 34.53 \mathrm{UC}$, seguido de TRH $25 \mathrm{~h}$ con $396.0 \pm 102.02$ UC y TRH $15 \mathrm{~h}$ con $402.5 \pm 79.29$ UC. El mayor valor de mediana fue el TRH $0 \mathrm{~h}$ con 965.6 $\pm 129.72 \mathrm{UC}$, que es el agua de entrada en los experimentos (figura 4). 
Figura 4. Valores de color en cada tratamiento. Contraste de medianas (mediana $\pm \mathrm{RI}$ )

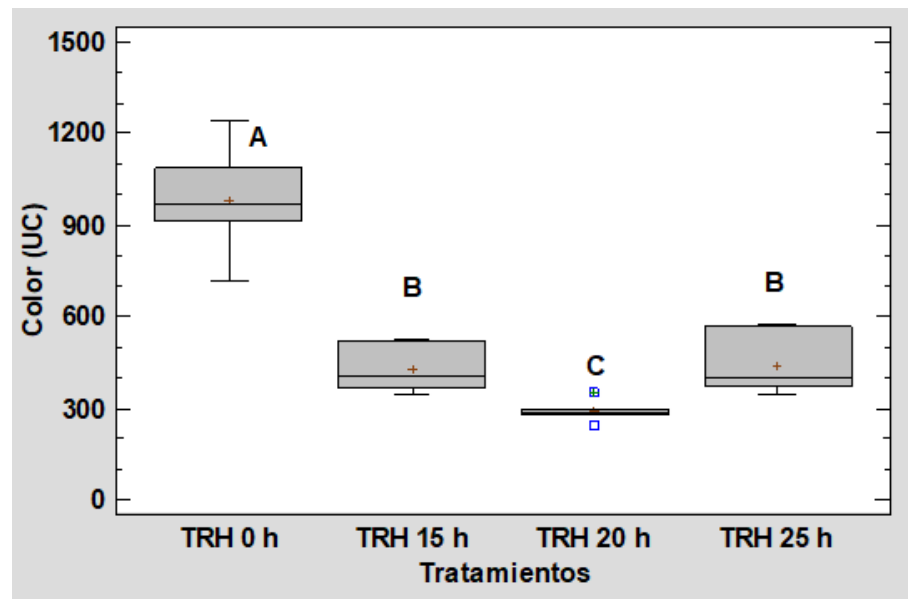

Nota: El tamaño de muestras compuestas es $N=18$ para cada tratamiento. Letras diferentes representan diferencias estadísticamente significativas.

Fuente: Elaboración propia

\section{pH}

La prueba de Kruskal-Wallis para $\mathrm{pH}$ muestra que existe una diferencia estadísticamente significativa entre las medianas. El tratamiento con el menor valor de mediana \pm DE fue TRH 15 h con $6.05 \pm 0.34 \mathrm{UpH}$, seguido de TRH 20 h con $6.15 \pm 0.77$ UpH y TRH 25 h con $6.2 \pm 0.19 \mathrm{UpH}$. El mayor valor de mediana fue el TRH 0 h con $7.8 \pm$ $0.85 \mathrm{UpH}$, que es el agua de entrada en los experimentos (figura 5).

Figura 5. Valores de $\mathrm{pH}$ en cada tratamiento. Contraste de medianas (mediana $\pm \mathrm{RI}$ )

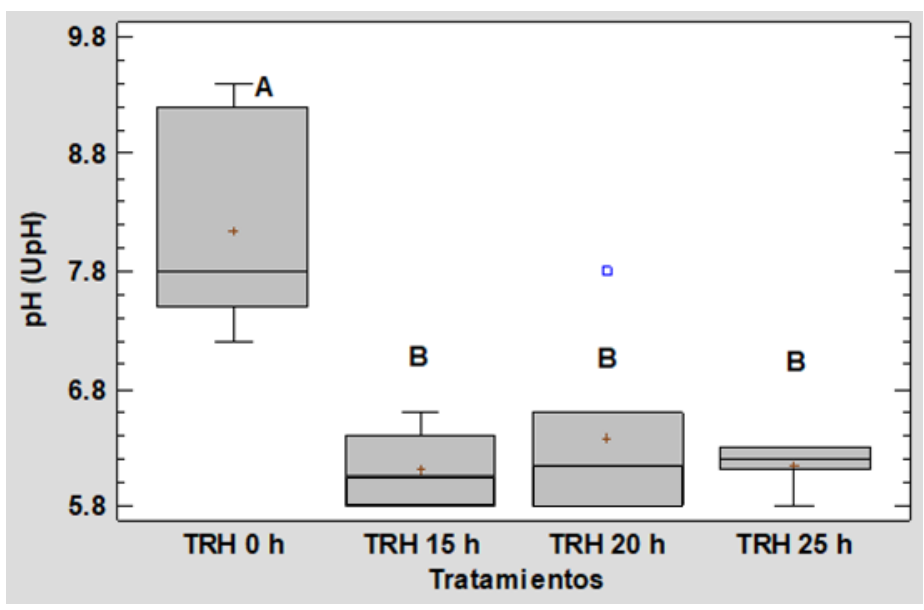

Nota: El tamaño de muestras compuestas es $N=18$ para cada tratamiento. Letras diferentes representan diferencias estadísticamente significativas.

Fuente: Elaboración propia 


\section{Temperatura}

La prueba de Kruskal-Wallis para temperatura muestra que existe una diferencia estadísticamente significativa entre las medianas. El tratamiento con el menor valor de mediana \pm DE fue TRH $0 \mathrm{~h}$ con $27.75 \pm 1.19^{\circ} \mathrm{C}$, seguido de TRH $25 \mathrm{~h}$ con $28.4 \pm 0.65{ }^{\circ} \mathrm{C} \mathrm{y}$ TRH $15 \mathrm{~h}$ con $28.7 \pm 1.69^{\circ} \mathrm{C}$. El mayor valor de mediana fue el TRH $30 \mathrm{~h}$ con $29.9 \pm 1.57$ ${ }^{\circ} \mathrm{C}$ (figura 6).

Figura 6. Valores de temperatura en cada tratamiento. Contraste de medianas (mediana \pm RI)

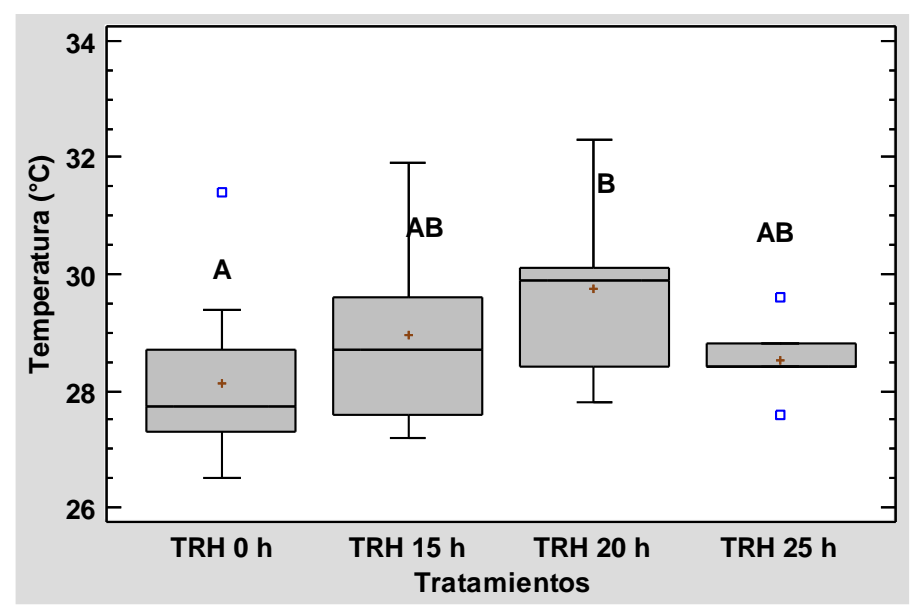

Nota: El tamaño de muestras compuestas es $N=18$ para cada tratamiento. Letras diferentes representan diferencias estadísticamente significativas.

Fuente: Elaboración propia

\section{Conductividad eléctrica}

La prueba de Kruskal-Wallis para CE muestra que existe una diferencia estadísticamente significativa entre las medianas. Los valores de mediana $\pm D E$ más bajos se presentaron en el tratamiento TRH $15 \mathrm{~h}(954.3 \pm 102.55 \mu \mathrm{S} / \mathrm{cm})$, seguido por TRH $25 \mathrm{~h}$ $(980.35 \pm 40.59 \mu \mathrm{S} / \mathrm{cm})$, TRH $20 \mathrm{~h}(1103.35 \pm 102.1 \mu \mathrm{S} / \mathrm{cm})$ y el valor más alto de mediana fue el TRH $0 \mathrm{~h}$ con $1500.5 \pm 199.78 \mu \mathrm{S} / \mathrm{cm}$ (figura 7 ). 
Figura 7. Valores de CE en cada tratamiento. Contraste de medianas (mediana $\pm \mathrm{RI}$ )

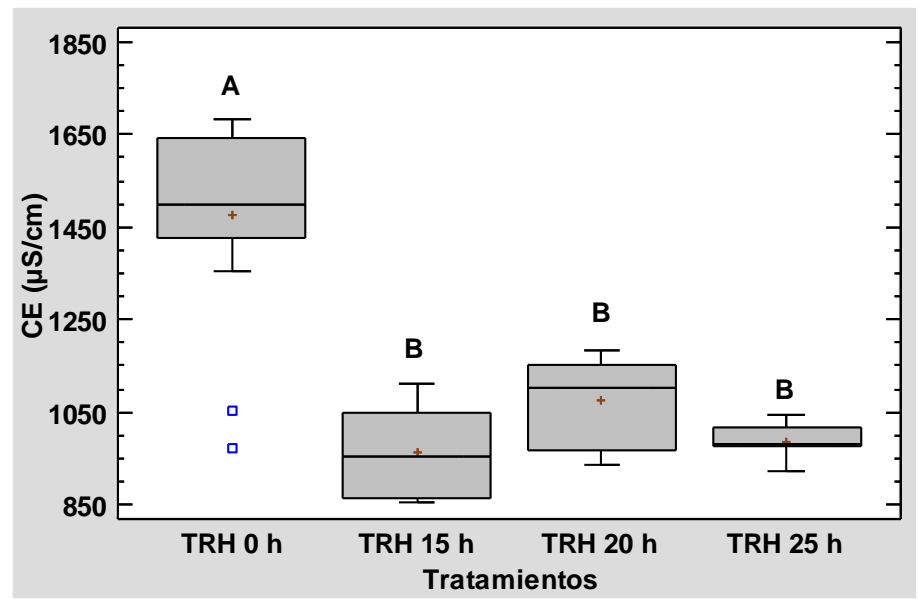

Nota: El tamaño de muestras compuestas es $N=18$ para cada tratamiento. Letras diferentes representan diferencias estadísticamente significativas.

Fuente: Elaboración propia

\section{Oxígeno disuelto}

La prueba de Kruskal-Wallis para OD muestra que existe una diferencia estadísticamente significativa entre las medianas. Los valores de mediana $\pm D E$ más bajos se presentaron en el tratamiento TRH $0 \mathrm{~h}(0.6 \pm 0.17 \mathrm{mg} / \mathrm{L})$, seguido por TRH $15 \mathrm{~h}(3.25 \pm 0.59$ $\mathrm{mg} / \mathrm{L})$, TRH $25 \mathrm{~h}(3.9 \pm 0.09 \mathrm{mg} / \mathrm{L})$ y el valor más alto de mediana fue el TRH $20 \mathrm{~h}$ con 4.2 $\pm 0.42 \mathrm{mg} / \mathrm{L}$ (figura 8 ).

Figura 8. Valores de OD en cada tratamiento. Contraste de medianas (mediana $\pm \mathrm{RI}$ )

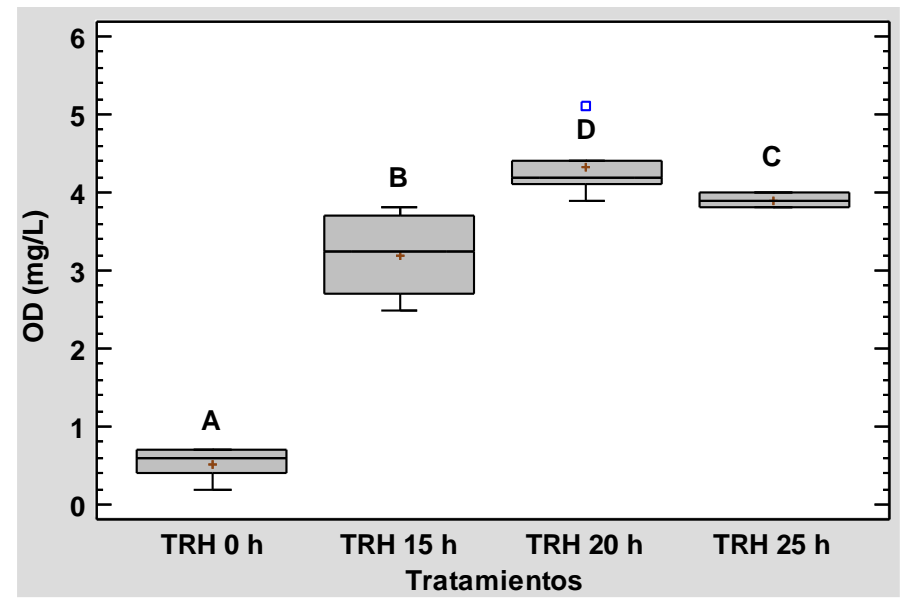

Nota: El tamaño de muestras compuestas es $N=18$ para cada tratamiento. Letras diferentes representan diferencias estadísticamente significativas. 
Fuente: Elaboración propia

\section{Demanda química de oxígeno}

El análisis de Kruskal Wallis de una vía muestra la existencia de una diferencia estadísticamente significativa entre las medianas de la variable de DQO de los tratamientos evaluados. Los valores de mediana $\pm D E$ más bajos se presentaron en el tratamiento TRH 20 $\mathrm{h}(35.6 \pm 2.98 \mathrm{mg} / \mathrm{L})$, seguido por TRH $15 \mathrm{~h}(63.9 \pm 14.54 \mathrm{mg} / \mathrm{L})$, TRH $25 \mathrm{~h}(78.05 \pm 12.91$ $\mathrm{mg} / \mathrm{L}$ ) y el valor más alto de mediana fue el TRH $0 \mathrm{~h}$ con $274.75 \pm 116.56 \mathrm{mg} / \mathrm{L}$, el cual es el agua de entrada a los tratamientos (figura 9).

Figura 9. Valores de DQO en cada tratamiento. Contraste de medianas (mediana $\pm \mathrm{RI}$ ).

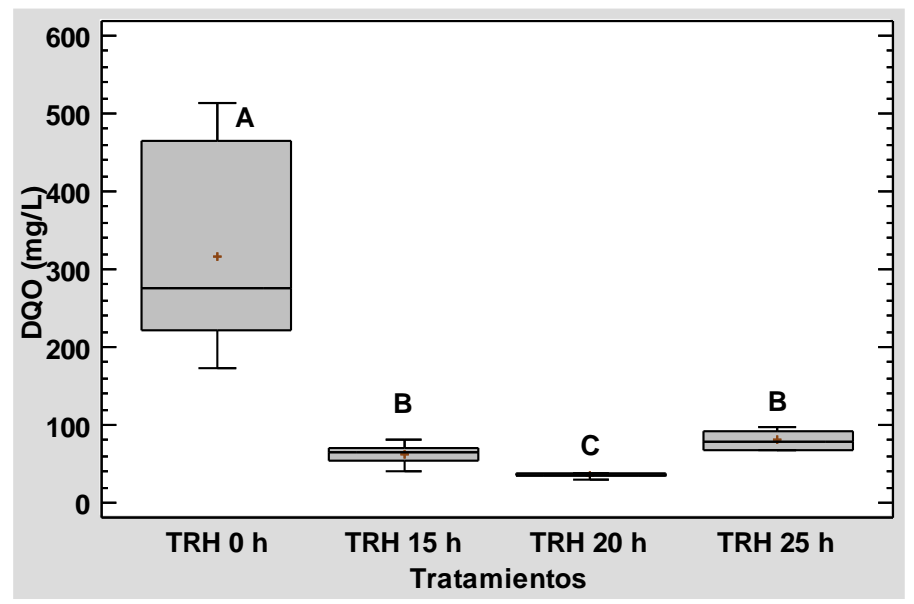

Nota: El tamaño de muestras compuestas es $N=18$ para cada tratamiento. Letras diferentes representan diferencias estadísticamente significativas.

Fuente: Elaboración propia

\section{Sólidos suspendidos totales}

El análisis de Kruskal Wallis de una vía muestra la existencia de una diferencia estadísticamente significativa entre las medianas de SST de los diferentes tratamientos evaluados. Los valores de mediana $\pm D E$ más bajos se presentaron en el tratamiento TRH 20 $\mathrm{h}(26.35 \pm 1.20 \mathrm{mg} / \mathrm{L})$, seguido por TRH $15 \mathrm{~h}(45.65 \pm 10.38 \mathrm{mg} / \mathrm{L})$, TRH $25 \mathrm{~h}(55.8 \pm 9.24$ $\mathrm{mg} / \mathrm{L}$ ) y el valor más alto de mediana fue el TRH $0 \mathrm{~h}$ con $196.25 \pm 81.43 \mathrm{mg} / \mathrm{L}$, el cual es el agua de entrada a los tratamientos (figura 10). 
Figura 10. Valores de SST en cada tratamiento. Contraste de medianas (mediana \pm RI)

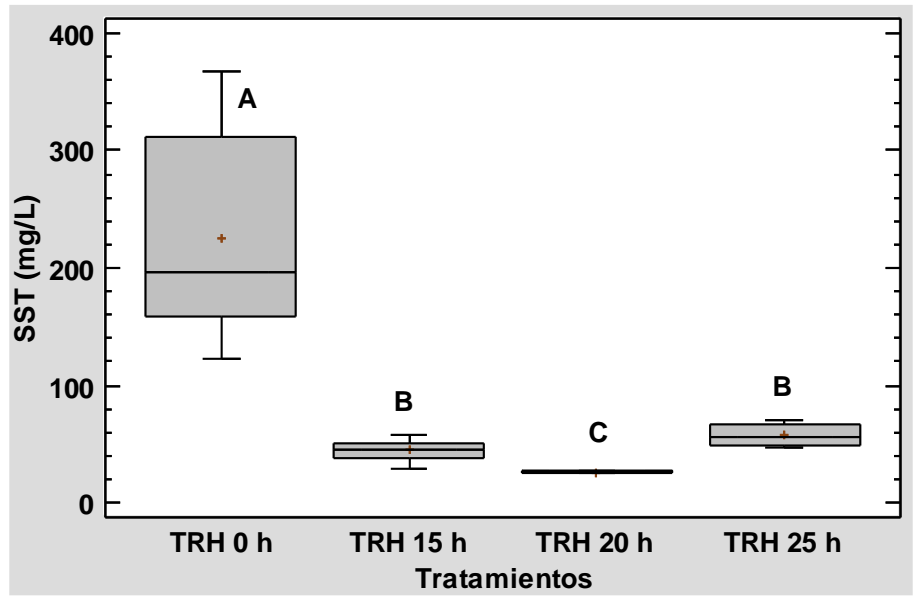

Nota: El tamaño de muestras compuestas es $N=36$ para cada tratamiento. Letras diferentes representan diferencias estadísticamente significativas.

Fuente: Elaboración propia

\section{Condiciones de operación y eficiencias de remoción de los tratamientos en el SBR}

Las condiciones de operación en cada uno de los tratamientos muestran comportamientos diferentes. El mejor tratamiento se suscitó en el experimento con 20 horas

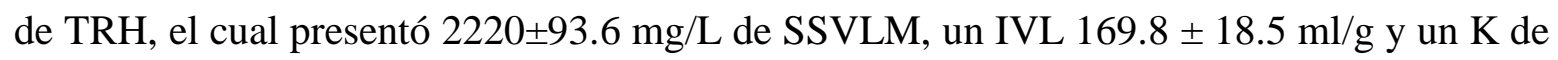
$20.8 \mathrm{~h}^{-1}$. Los demás parámetros y condiciones de los experimentos se presentan en la tabla 5. La concentración de los SSVLM dobla a la reportado en otros estudios con lodos activados que utilizan alrededor de $1071 \mathrm{mg} / \mathrm{L}$ (Flores, Cuevas y González, 2019), pero es menor a la que se reporta en el tratamiento de aguas residuales de tipo industrial de Amorim et al. (2016). El índice volumétrico del lodo (IVL) está dentro del rango moderado en características de compactación y de sedimentación de los lodos (Ferrara y Ramírez, 2013). 
Tabla 5. Condiciones de operación del SBR bajo diferentes TRH. $(N=18)$.

\begin{tabular}{|l|c|c|c|c|c|c|}
\hline \multirow{2}{*}{ Parámetro } & \multicolumn{2}{|c|}{ TRH-15 h } & \multicolumn{2}{c|}{ TRH-20 h } & \multicolumn{2}{c|}{ TRH-25 h } \\
\cline { 2 - 7 } & $\boldsymbol{X}$ & $\pm \boldsymbol{D E}$ & $\boldsymbol{X}$ & $\pm \boldsymbol{D E}$ & $\boldsymbol{X}$ & $\pm \boldsymbol{D E}$ \\
\hline SSVLM (mg/L) & $2,169.4$ & 162.8 & $2,220.0$ & 93.6 & $2,208.2$ & 106.4 \\
\hline DQO influente (mg/L) & 247.6 & 57.4 & 229.1 & 21.0 & 217.7 & 33.0 \\
\hline DQO efluente (mg/L) & 61.1 & 14.5 & 35.2 & 3.0 & 81.7 & 12.9 \\
\hline $\mathrm{q}, n=1\left(\mathrm{~h}^{-1} \mathrm{~L} \mathrm{mg}^{-1}\right)$ & 1.3 & 0.3 & 1.6 & 0.2 & 1.5 & 0.4 \\
\hline $\mathrm{K}\left(\mathrm{h}^{-1}\right)$ & 45.5 & & 20.8 & & 47.0 & \\
\hline IVL $(\mathrm{ml} / \mathrm{g})$ & 152.4 & 12.7 & 169.8 & 18.5 & 77.3 & 12.4 \\
\hline
\end{tabular}

Fuente: Elaboración propia

Finalmente, las eficiencias de remoción de los parámetros de control de procesos de calidad del agua muestran que el tratamiento TRH 20 h presentó la mayor eficiencia con 92.1\% para turbiedad, $71.3 \%$ para color, $31.2 \%$ para $\mathrm{pH},-6.1 \%$ para temperatura, $35.2 \%$ para CE, $-1371.6 \%$ para OD, $92.4 \%$ para DQO y $92 \%$ para SST. Es importante aclarar que el signo negativo (-) en la eficiencia de remoción nos indica que el valor del parámetro es más alto en la salida y es menor en la entrada, importante para el caso de la temperatura, que nos muestra el incremento de este valor en el efluente, y en el caso del OD hay mayor concentración en el efluente como producto de la aireación en el proceso. La eficiencia de los diferentes tratamientos se presenta en la tabla 6 . 
Tabla 6. Eficiencias de remoción de contaminantes básicos del SBR operado bajo diferentes TRH $(N=18)$

\begin{tabular}{|l|c|c|c|}
\hline \multicolumn{1}{|c|}{ Parámetro } & TRH 15 h & TRH 20 h & TRH 25 h \\
\cline { 2 - 4 } & ER (\%) & ER (\%) & ER (\%) \\
\hline Turbiedad (UNT) & 75.8 & 92.1 & 66.2 \\
\hline Color (UC) & 59.9 & 71.3 & 49.2 \\
\hline pH & 18.4 & 31.2 & 19.8 \\
\hline Temperatura $\left({ }^{0} \mathrm{C}\right)$ & 0.2 & -6.1 & -4.5 \\
\hline CE $(\mu$ S/cm) & 26.1 & 35.2 & 32.8 \\
\hline OD $(\mathrm{mg} / \mathrm{L})$ & -413.4 & -1371.6 & -522.3 \\
\hline DQO $(\mathrm{mg} / \mathrm{L})$ & 75.8 & 92.4 & 64.5 \\
\hline SST $(\mathrm{mg} / \mathrm{L})$ & 75.8 & 92.0 & 64.5 \\
\hline
\end{tabular}

Fuente: Elaboración propia

\section{Discusión}

\section{Turbiedad y color}

El color y la turbiedad son parámetros de rápida determinación para el control del proceso en sistemas de tratamiento de aguas residuales. Están relacionados con la presencia de sólidos suspendidos en el agua residual (Ortiz, López, Torres y Pampillón, 2018). Valores de turbiedad elevados en el efluente indican altas concentraciones de sólidos suspendidos (después de la sedimentación) y es una indicación obvia del mal funcionamiento del sistema (Conagua, 2016). Durante la fase experimental, el SBR TRH 20 h presentó los valores más bajos (promedio $\pm D E$ ) de color y turbiedad con $9.6 \pm 0.8$ UNT y $291.4 \pm 34.5 \mathrm{UC}$; el valor máximo se presentó en TRH 25 h con $21.3 \pm 3.4$ UNT y $442.2 \pm 102.0$ UC. La eficiencia de remoción para el TRH $20 \mathrm{~h}$ fue de $92.1 \%$ en turbiedad y $71.3 \%$ en color; mientras el TRH 15 h alcanzó $75.8 \%$ de turbiedad y de color $59.9 \%$. El tratamiento TRH 25 h logró una eficiencia de remoción de $66.2 \%$ para turbiedad y $49.2 \%$ para color.

Carrasquero et al. (2014) trataron agua residual de matadero de reses en un SBR y reportaron que TRH de 10 y 12 horas son suficientes para alcanzar $73 \%$ (influente 2875 UCefluente 781 UC) y $91 \%$ (influente 4125 UC-efluente 344 UC) de color respectivamente; para turbiedad se removió $85 \%$ (influente 232 UNT-efluente 25 UNT) y $77 \%$ (influente 99 UNT-efluente $23 \mathrm{UNT}$ ) respectivamente, lo que muestra que no hay diferencias significativas 
Revista Iberoamericana de las Ciencias Biológicas y Agropecuarias

entre los tratamientos (10 y $12 \mathrm{~h}$ ) con $p \leq 0.05$. En nuestro caso, para turbiedad y color hay diferencia estadística $(p<0.05)$ entre los tres tratamientos $(0,15,20$ y 25 horas); el TRH 20 h es el más eficiente ya que logró la concentración más baja.

\section{pH}

El rango óptimo de $\mathrm{pH}$ para asegurar la actividad y el desarrollo de los microorganismos en el SBR está entre 6.0 y 8.5 unidades, valores en los que debe estar el agua residual a tratar y el sistema en el tanque de aireación, pues favorece los procesos de degradación de materia orgánica, nitrificación y desnitrificación (Conagua, 2016). Este intervalo es similar al criterio de descarga que establece la NOM-001-SEMARNAT-1996 (6.5 a 10 unidades) y en los efluentes de este estudio se presentó un rango de 6.1 a 6.4 unidades. Un cambio del $\mathrm{pH}$ al establecido puede generar un impacto en toda la biota y aunque las bacterias pueden sobrevivir entre 5.0 y 10.0 unidades no podrán reproducirse, lo que ocasiona que los microorganismos mueran, y si el pH está por debajo de 6.5, los hongos predominarán sobre las bacterias y se tendrá una baja remoción de DBO y una pobre sedimentación (Conagua, 2016). Los resultados en este estudio para pH, aunque están ligeramente por debajo del rango establecido por la NOM-001-SEMARNAT-1996, sí están en el rango establecido en el manual de la Conagua (2016) para procesos óptimos de lodos activados (o sus variantes) y no hay una diferencia significativa $(p<0.05)$ de la variable $\mathrm{pH}$ entre los tres TRH $(15,20$ y 25 h); aquí el diferente es el TRH 0 h.

\section{Temperatura}

La temperatura es un parámetro importante de operación de los SBR debido a que tiene un efecto directo en la actividad bacteriana y a raíz de que operacionalmente no se tiene control sobre este. El rango óptimo para la actividad bacteriana aerobia está entre 25 y $32{ }^{\circ} \mathrm{C}$. Con altas temperaturas las bacterias se vuelven más activas; y a bajas temperaturas, menos activas. Sin embargo, arriba de $35^{\circ} \mathrm{C}$ las enzimas son destruidas, lo que da como resultado una baja en la eficiencia de remoción de contaminantes en el proceso (Conagua, 2016). Este parámetro se encuentra regulado para su descarga por la NOM-001-SEMARNAT-1996, la cual establece para ciertos cuerpos receptores un límite máximo permisible de $40{ }^{\circ} \mathrm{C}$, temperatura que no se alcanzó en todo el proceso de evaluación, pues en el influente el rango fue de 27 a $29{ }^{\circ} \mathrm{C}$, mientras que en el efluente de los tratamientos se presentó un rango de 
28.5 a $29.7^{\circ} \mathrm{C}$. Los resultados presentados en el experimento son buenos, pues la temperatura del agua residual no excedió $\operatorname{los} 35^{\circ} \mathrm{C}$ ni fue menor a $15^{\circ} \mathrm{C}$, condiciones que deben tener las plantas en su operación, ya que esto garantiza la presencia de bacterias mesófilas (Carrasquero, Rodríguez, Bernal y Díaz, 2018). En este caso, no hay una diferencia estadística significativa ( $p \geq 0.05$ ) en la variable temperatura, pero el TRH $20 \mathrm{~h}$ es eficiente para el desarrollo de los microorganismos.

\section{Conductividad eléctrica}

La conductividad eléctrica del agua es la capacidad de transportar la corriente eléctrica por los iones presentes en esta. El aumento en la concentración de iones provoca el incremento de la conductividad (Crites y Tchobanoglous, 2000). Este parámetro es importante de medir para ver la posibilidad de reúso del agua tratada en riego. Si el agua de riego tiene una conductividad eléctrica $(\mathrm{CE})$ menor que $0.7 \mathrm{dS} / \mathrm{m}(<700 \mu \mathrm{S} / \mathrm{cm})$, se podrán regar casi todos los cultivos, excepto aquellos muy sensibles a sales; pero si la CE se encuentra en el rango de 0.7 a $3.0 \mathrm{dS} / \mathrm{m}$ (700 a $3000 \mu \mathrm{S} / \mathrm{cm})$, solo se recomienda sembrar aquellos cultivos que tengan de buena a moderada tolerancia a la salinidad (Cisneros y Saucedo, 2016). En nuestro caso, los tratamientos presentaron efluentes en el rango de 964.5 $\mu \mathrm{S} / \mathrm{cm}$ a $1075.2 \mu \mathrm{S} / \mathrm{cm}$ : en grado de restricción para su uso de ligero a moderado según lo establece la Food and Agriculture Organization (FAO) (Ayers y Westcot, 1994). Podemos observar que no hay una diferencia significativa de la variable CE entre los tres TRH (15, 20 y 20 h) ( $p<0.05)$; diferente es el agua de entrada, que se evaluó como un tratamiento en el experimento.

\section{Oxígeno disuelto}

El OD en el SBR es muy importante para la operación. Si el OD es muy bajo, se inhibe la actividad microbiana y la remoción de materia orgánica baja; si se incrementa el OD, puede deberse a una mortandad alta de microorganismos, y una caída brusca de OD indica que gran cantidad de materia orgánica ingresó al sistema, por lo que se recomienda tener OD residual de uno a dos mg/L en el aireador (Araya et al., 2014; Conagua, 2016). En nuestros experimentos, los SBR operaron con una concentración de OD de cuatro a seis $\mathrm{mg} / \mathrm{L}^{-1}$, como se recomienda para el tratamiento de aguas residuales municipales y para algunas aguas industriales (Carrasquero et al., 2018; Zhang, Jiang, Xu, Wang, Xie, 2017). El 
Revista Iberoamericana de las Ciencias Biológicas y Agropecuarias

agua de entrada a los SBR presentó valores bajos de OD, pues adquirió características sépticas por la temperatura $\left(32^{\circ} \mathrm{C}\right.$ ambiente) y TRH en el cárcamo cisterna del campus (45 minutos). Las concentraciones altas de OD pueden afectar negativamente la sedimentación, debido a que la mezcla puede romper los flóculos. Los lodos con esponjamiento son el resultado de aguas residuales tratadas en un proceso con deficiencia de oxígeno o nutrientes, que está asociado a la presencia de microorganismos de naturaleza filamentosa (Pacheco, Jáuregui, Pavón y Mejía, 2003). Sin embargo, en nuestro caso, la concentración de OD en el efluente se encontró en un rango de 3.2 a $4.3 \mathrm{mg} / \mathrm{L}$, y mostró diferencias $(p<0.05)$ entre los tratamientos; el TRH $20 \mathrm{~h}$ fuel el óptimo con una mediana de $4.2 \mathrm{mg} / \mathrm{L}$.

\section{Demanda química de oxígeno}

La DQO es un parámetro que cada vez tiene mayor uso, ya que su análisis es mucho más rápido que el de la DBO y nos permite determinar la materia inorgánica y orgánica no putrescible, susceptible a ser oxidada químicamente por dicromato en un medio ácido; permite, además, evaluar la eficiencia de una planta en menor tiempo, lo cual es vital en la toma de decisiones (Crites y Tchobanoglous, 2000). Teniendo en cuenta lo anterior, Carrasquero et al. (2018) evaluaron la eficiencia de un reactor biológico secuencial en el tratamiento de efluentes de una planta procesadora de productos cárnicos, con tres diferentes TRH $(7,10$ y 12 h) y la variable de DQO como parámetro principal en el control del proceso. El influente presentó una variación entre 1234 a $1825 \mathrm{mg} / \mathrm{L}$, los tratamientos alcanzaron $92.6 \%(7 \mathrm{~h}), 91.9 \%(10 \mathrm{~h})$ y $91.3 \%(12 \mathrm{~h})$ de eficiencia de remoción de DQO y no se encontraron diferencias significativas entre los tres tiempos evaluados $(p \leq 0.05)$. Aunque en nuestro estudio las aguas residuales son de carácter doméstico, las eficiencias de remoción para QDO para el mejor tratamiento son similares a las de Carrasquero et al., (2018), pues el experimento con TRH 15 h obtuvo $75.8 \%$, el TRH 20 h con $92.4 \%$ y el TRH 25 con $64.5 \%$.

Es importante resaltar que en un sistema de tratamiento es más difícil alcanzar eficiencias de remoción altas de un contaminante cuando el influente presenta bajas concentraciones o calidad de agua media-débil (Tchobanoglous et al., 2003). El agua residual doméstica presenta mayor cantidad de sustancias que en un matadero y el SBR no es aplicable a todo tipo de efluente orgánico, la presencia de compuestos tóxicos puede afectar negativamente el desempeño de este tipo de tratamiento (Martínez, Calderón y Ruiz, 2017). Esto queda demostrado por Nava, Gasperín y Durán (2014), quienes trataron agua residual 
Revista Iberoamericana de las Ciencias Biológicas y Agropecuarias

de una refinería en un SBR cuya concentración de entrada fue de $487 \pm 42 \mathrm{mg} / \mathrm{L}$, y obtuvieron un efluente de $119 \pm 30 \mathrm{mg} / \mathrm{L}$, lo que representa una remoción de DQO de $75 \%$, por la presencia de fenoles. Finalmente, el proyecto de norma PROY-NOM-001-SEMARNAT2017 (Semarnat, 5 de enero de 2018) fija el límite de descarga a zonas marinas y estuarios en $85 \mathrm{mg} / \mathrm{L}$ de DQO, valor que cumplieron satisfactoriamente los tres tratamientos evaluados.

\section{Sólidos suspendidos totales}

El comportamiento del influente para el parámetro de SST presentó una variabilidad de 162 a 328 mg/L, concentración típica de un agua residual con características domésticas. El mejor tratamiento se presentó en el TRH 20 h con un efluente promedio de $26.1 \pm 1.2$ $\mathrm{mg} / \mathrm{L}$, lo que le permitió alcanzar una eficiencia de remoción de 92\% de SST y cumplir con el criterio de descarga para protección de vida acuática, que permite descargar $40 \mathrm{mg} / \mathrm{L}$ (NOM-001-SEMARNAT-1996); los otros tratamientos están por arriba de esta concentración. Derlon, Wagner, Ribeiro da Costa y Morgenroth (2016) evaluaron la formación de gránulos aeróbicos en el tratamiento de aguas residuales municipales de baja resistencia utilizando un reactor por lotes secuencial a volumen constante, y reportaron (influente $140 \pm 30 \mathrm{mg} / \mathrm{L}$ ) que pudieron reducir la concentración de su efluente a concentraciones menores a $10 \mathrm{mg} / \mathrm{L}$ de SST, al realizar una selectiva utilización de carbono orgánico durante la alimentación anaeróbica.

\section{Conclusión}

La biomasa activa de ganado vacuno en el tratamiento de aguas residuales domésticas en SBR es eficiente en la remoción de contaminantes básicos y parámetros de control de las aguas residuales domésticas y favorece los tiempos y costos de operación.

Los experimentos muestran que es posible utilizar un TRH de 20 horas con agua residual con características de carga media para alcanzar eficiencias de $92 \%$ en remoción de la DQO. El incremento en el tiempo de retención disminuye la remoción de este parámetro.

Se debe garantizar una adecuada aireación (cuatro a seis mg/L de OD) en el sistema para evitar la baja remoción de contaminantes por el incremento de microorganismos filamentosos, lo que provoca el incremento de SST en el efluente. 
Finalmente, podemos recomendar la implementación del uso de los SBR para el tratamiento de efluentes domésticos en sistemas descentralizados del sureste de México como una alternativa viable en el tratamiento de sus aguas residuales.

\section{Referencias}

2120 Color. (2017). Standard Methods For the Examination of Water and Wastewater. Retrieved from https://www.standardmethods.org/doi/10.2105/SMWW.2882.017.

2510 Conductivity. (2017). Standard Methods For the Examination of Water and $\begin{array}{lll}\text { Wastewater. } & \text { Retrieved }\end{array}$ https://www.standardmethods.org/doi/abs/10.2105/SMWW.2882.027.

2550 Temperature. (2017). Standard Methods For the Examination of Water and Wastewater. $\quad$ Retrieved from https://www.standardmethods.org/doi/abs/10.2105/SMWW.2882.031.

4500-H+ pH Value. (2017). Standard Methods For the Examination of Water and Wastewater. $\quad$ Retrieved from https://www.standardmethods.org/doi/10.2105/SMWW.2882.082.

4500-O Oxygen (Dissolved). (2017). Standard Methods For the Examination of Water and Wastewater. $\quad$ Retrieved from https://www.standardmethods.org/doi/10.2105/SMWW.2882.091.

Amorim, C. L., Moreira, I. S., Ribeiro, A. R., Santos, L., Delerue, C., Tiritan, M. E. and Castro, P. (2016). Treatment of a simulated wastewater amended with a chiral pharmaceuticals mixture by an aerobic granular sludge sequencing batch reactor. International Biodeterioration \& Biodegradation, 115, 277-285. Retrieved from http://dx.doi.org/10.1016/j.ibiod.2016.09.009.

Araya, F., Vera, L., Morales, G., López, D. y Vidal G. (2014). Tecnologías de tratamiento para aguas servidas de origen rural. En Vidal, G. y Araya, F. (ed. ${ }^{\text {as }}$ ), Las aguas servidas y su depuración en zonas rurales: Situación actual y desafíos (1. ${ }^{\mathrm{a}} \mathrm{ed}$.). Chile: Editorial Universidad de Concepción. Recuperado de http://www.eula.cl/giba/wpcontent/uploads/2017/09/las-aguas-servidas-y-su-depuracion-en-zonas-ruralessituacion-actual-y-desafios.pdf.

Ayers, R.S. y Westcot, D.W. (1994). Water quality for agriculture. Estudio FAO: Riego y Drenaje 29, Rev. 1. Roma: Food and Agriculture Organization. FAO Irrigation and 
Drainage Paper. Food and Agriculture Organization of the United Nations Rome. ISBN 92-5-102263-1. Recuperado de http://www.fao.org/3/T0234E/T0234E00.htm

Carrasquero, S., Matos, E., Saras, F., Pire, M., Colina, G. y Díaz, A. (2014). Evaluación de la eficiencia de un reactor por carga secuencial tratando aguas residuales provenientes de un matadero de reses. Revista de la Facultad de Ingeniería Universidad Central de Venezuela, 29(3), 7-16. Recuperado de http://ve.scielo.org/scielo.php?script=sci_arttext\&pid=S0798$40652014000300002 \& \operatorname{lng}=$ es\&tlng=es.

Carrasquero, S. J., Rodríguez, M. G., Bernal, J. A. y Díaz, R. (2018). Eficiencia de un reactor biológico secuencial en el tratamiento de efluentes de una planta procesadora de productos cárnicos. Revista Facultad de Ciencias Básicas, 14(1), 23-33. Recuperado de http://dx.doi.org/10.18359/rfcb.xxxx.

Cisneros, O. X. y Saucedo, H. E. (2016). Reúso de aguas residuales en la agricultura. México: Instituto Mexicano de Tecnología del Agua. Coordinación de Riego y Drenaje. Recuperado de https://www.imta.gob.mx/biblioteca/libros_html/riegodrenaje/reuso-aguas-residuales.pdf.

Comisión Nacional del Agua [Conagua]. (2015). Inventario nacional de plantas municipales de potabilización y de tratamiento de aguas residuales en operación. Diciembre 2015. México: Comisión Nacional del Agua. Recuperado de https://www.gob.mx/cms/uploads/attachment/file/197610/Inventario_2015.pdf.

Comisión Nacional del Agua [Conagua]. (2016). Manual de agua potable, alcantarillado y saneamiento. Diseño de plantas de tratamiento de aguas residuales municipales: lodos activados. México: Comisión Nacional del Agua. Recuperado de http://cmx.org.mx/wp-content/uploads/MAPAS\%202015/libros/SGAPDS-1-15Libro51.pdf.

Crites, R. y Tchobanoglous, G. (2000). Sistemas de manejo de aguas residuales para núcleos pequeños y descentralizados. Colombia: McGraw-Hill.

Derlon, N., Wagner, J., Ribeiro da Costa, R. J. and Morgenroth E. (2016). Formation of aerobic granules for the treatment of real and low-strength municipal wastewater using a sequencing batch reactor operated at constant volume. Water Research, 105, 341-350. Retrieved from http://dx.doi.org/10.1016/j.watres.2016.09.007. 
Environmental Protection Agency [EPA]. (1983). Turbidity (Nephelometric) Methods for Chemical Analysis of Water and Wastes. Environmental Monitoring and Supporting Laboratory. Cincinnati, United States: Environmental Protection Agency.

Environmental Protection Agency [EPA]. (1999). Folleto informativo de tecnología de aguas residuales Reactores secuenciales por tandas. Washington, United States: Office of Water.

Retrieved

from https://nepis.epa.gov/Exe/ZyPDF.cgi/P1007MHF.PDF?Dockey=P1007MHF.PDF.

O'Dell, J. W. (ed.) (1993). Method 410.4, Revision 2.0: The Determination of Chemical Oxygen Demand by SemiAutomated Colorimetry. Cincinnati, United States: Environmental Protection Agency. Retrieved from https://www.epa.gov/sites/production/files/2015-08/documents/method_4104_1993.pdf.

Ferrara, G. y Ramírez, A. (2013). Análisis de la sedimentabilidad de los lodos biológicos producidos en un RCS durante la desnitrificación de un efluente de un biorreactor de crecimiento adherido. Revista de la Facultad de Ingeniería, 28(1), 37-44. Recuperado de http://ve.scielo.org/scielo.php?script=sci_arttext\&pid=S079840652013000100005 .

Flores, M. G., Cuevas, G. y González, G. (2019). Comparación de un biorreactor con membranas sumergidas con un sistema convencional de lodos activados para el tratamiento de aguas residuales. Revista Internacional de Contaminación Ambiental, 35, 57-64. Recuperado de revistascca.unam.mx/rica/index.php/rica/article/view/RICA.2019.35.esp03.07.

Ghizellaoui, S. and Ghizellaoui, S. (2010). Evaluation of the quality of waters treated by the activated muds station in Oued El Athmania. Desalination, 250(1), 438-443.

Li, J., Healy, M., Zhan, X. and Rodgers, M. (2008). Nutrient removal from slaughterhouse wastewater in an intermittently aerated sequencing batch reactor. Bioresource Technology, 99(16), 7644-7650. Retrieved from https://doi.org/10.1016/j.biortech.2008.02.001.

Levin, M. y Gealt, M. A. (1997). Biotratamiento de residuos tóxicos y peligrosos. Selección, estimación, modificación de microorganismos y aplicaciones. Madrid, España: McGraw-Hill. 
Martínez, P., Calderón, C. y Ruiz C. (2017). Metodología para el diseño de un biorreactor secuencial. Ingenium. Revista de la Facultad de Ingeniería, 18(36), 11-25. Recuperado de http://revistas.usbbog.edu.co/index.php/Ingenium/article/view/3428.

Méndez, L., Miyashiro, V., Rojas, R., Cotrado, M. y Carrasco, N. (2004). Tratamiento de aguas residuales mediante lodos activados a escala de laboratorio. Revista del Instituto de Investigación de la Facultad de Ingeniería Geológica, Minera, Metalúrgica y Geográfica, 7(14), 74-83. Recuperado de https://doi.org/10.15381/iigeo.v7i14.734.

Nájera, M. C. (2012). Efectos de la aplicación de altas cargas orgánicas en sistemas de lodos activados. (tesis de maestría inédita). Universidad Nacional Autónoma de México, México. Recuperado de http://www.ptolomeo.unam.mx:8080/xmlui/bitstream/handle/132.248.52.100/5073/t esis.pdf.pdf?sequence=1.

Nava, L. M., Gasperín, R. y Durán, A. (2014). Comparación de un reactor de biomasa suspendida y un reactor de biomasa adherida para la biodegradación de compuestos tóxicos presentes en aguas residuales de refinerías de petróleo. Revista Internacional de Contaminación Ambiental, 30(1) 101-112. Recuperado de https://www.revistascca.unam.mx/rica/index.php/rica/article/view/35724.

Noyola, A., Morgan, J. M. y Güereca, L. P. (2013). Selección de tecnologías para el tratamiento de aguas residuales municipales. Guía de apoyo para ciudades pequeñas y medianas. Ciudad de México, México. UNAM-Instituto de Ingeniería. Recuperado de http://proyectos2.iingen.unam.mx/LACClimateChange/docs/Guia.pdf.

Ortiz, V., López, G., Torres, C. A. y Pampillón, L. (2018). Almidón de yuca (Manihot esculenta Crantz) como coadyuvante en la coagulación floculación de aguas residuales domésticas. Revista Iberoamericana de las Ciencias Biológicas y Agropecuarias, 7(13), 18-46.

Pacheco, V. F., Jáuregui, B, Pavón, T. B. y Mejía, G. V. (2003). Control del crecimiento de microorganismos filamentosos en una planta de tratamiento de aguas residuales industriales. Revista Internacional de Contaminación Ambiental, 19(1), 47-53.

Pire, M. C., Palmero, J., Araujo, I. y Díaz A. (2010). Tratabilidad del efluente de una tenería con presencia de cromo usando un reactor por carga secuencial. Revista Científica, 20(4), 390-398.

Recuperado

de 
http://ve.scielo.org/scielo.php?script=sci_arttext\&pid=S079822592010000400009\&lng=es\&tlng=es.

Secretaría de Economía. (s. f.). NMX-AA-034-SCFI-2001. Análisis de agua. Determinación de sólidos y sales disueltas en aguas naturales, residuales y residuales tratadas. Recuperado de https://agua.org.mx/wp-content/uploads/2011/01/nmx-aa-034-scfi2001.pdf

Secretaría de Medio Ambiente y Recursos Naturales [Semarnat]-Comisión Nacional del Agua [Conagua]. (s. f.). Normas Oficiales Mexicanas. NOM-001-SEMARNAT1996. NOM-002-SEMARNAT-1996. NOM-003-SEMARNAT-1997. México: Secretaría de Medio Ambiente y Recursos Naturales-Comisión Nacional del Agua. Recuperado de http://www.conagua.gob.mx/CONAGUA07/Publicaciones/Publicaciones/SGAA15-13.pdf.

Secretaría de Medio Ambiente y Recursos Naturales [Semarnat]. (5 de enero de 2018). Proyecto de Modificación de la Norma Oficial Mexicana NOM-001-SEMARNAT1996, que establece los límites máximos permisibles de contaminantes en las descargas de aguas residuales en aguas y bienes nacionales para quedar como proyecto de modificación de la Norma Oficial Mexicana PROY-NOM-001SEMARNAT-2017, que establece los límites permisibles de contaminantes en las descargas de aguas residuales en cuerpos receptores propiedad de la nación. Diario Oficial de la Federación. Recuperado de https://www.dof.gob.mx/nota_detalle.php?codigo=5510140\&fecha=05/01/2018.

Tchobanoglous, G., Burton, F. L. and Stensel, H. D. (2003). Wastewater Engineering: Treatment and Reuse. McGraw-Hill.

Vázquez, M. B. y López, G. (2011). Evaluación técnica de un tanque Imhoff para el tratamiento de aguas residuales en centro, Tabasco. Unacar Tecnociencia, 5(1) 3247. Recuperado de http://www.unacar.mx/contenido/tecnociencia/tecnociencia_enero_junio11/tema_5_ evaluacion_tecnica_de_un_tanque.pdf.

Zhang, Y., Jiang, W. L, Xu, R. X., Wang, G. X. and Xie, B. (2017). Effect of short-term salinity shock on unacclimated activated sludge with pressurized aeration in a 
sequencing batch reactor. Separation and Purification Technology, 178, 200-206. Retrieved from http://dx.doi.org/10.1016/j.seppur.2017.01.048.

\section{Carlos Alberto Torres Balcázar}

Maestro en Ciencias en Ingeniería Ambiental por el Instituto Tecnológico y de Estudios Superiores de Monterrey e ingeniero Industrial Químico por el Instituto Tecnológico de Celaya. Es profesor-investigador de tiempo completo y miembro del cuerpo académico de Ingeniería y Tecnología Ambiental.

\section{Gaspar López Ocaña}

Doctor en Ciencias en Ecología y Manejo de Sistemas Tropicales, maestro en Ingeniería y Protección Ambiental e ingeniero Ambiental, todos los grados por la Universidad Juárez Autónoma de Tabasco (UJAT). Es profesor-investigador de tiempo completo, miembro del cuerpo académico de Ingeniería y Tecnología Ambiental y responsable del Laboratorio de Tecnología del Agua de la División Académica de Ciencias Biológicas (DACBiol) de la UJAT.

\section{Mario José Romellón Cerino}

Maestro en Ingeniería y Protección Ambiental e ingeniero Ambiental, ambos por la Universidad Juárez Autónoma de Tabasco (UJAT). Es profesor-investigador de tiempo completo en el Instituto Tecnológico de Villahermosa.

\section{María Berzabé Vázquez González}

Maestra en Ingeniería y Protección Ambiental por la Universidad Juárez Autónoma de Tabasco (UJAT) e ingeniera Industrial Químico por el Instituto Tecnológico de Villahermosa. Es profesora-investigadora de tiempo completo en el Instituto Tecnológico de Villahermosa.

\section{Luis Enrique Comparán Sánchez}

Estudiante de la maestría en Ingeniería, Tecnología y Gestión Ambiental de la Universidad Juárez Autónoma de Tabasco (UJAT) e ingeniero Ambiental por la UJAT. Es colaborador del Laboratorio de Tecnología del Agua de la División Académica de Ciencias Biológicas (DACBiol) de la UJAT. 
Revista Iberoamericana de las Ciencias Biológicas y Agropecuarias

\begin{tabular}{|l|l|}
\hline Rol de contribución & Autor(es) \\
\hline Conceptualización & Carlos Alberto Torres Balcázar 50\% Gaspar López Ocaña 50\% \\
\hline Metodología & $\begin{array}{l}\text { Gaspar López Ocaña 60\% Carlos Alberto Torres Balcázar 10\% } \\
\text { Mario José Romellón Cerino 10\% María Berzabé Vázquez } \\
\text { González 10\% Luis Enrique Comparán Sánchez 10\% }\end{array}$ \\
\hline Software & $\begin{array}{l}\text { Gaspar López Ocaña 60\% Carlos Alberto Torres Balcázar 10\% } \\
\text { Mario José Romellón Cerino 10\% María Berzabé Vázquez } \\
\text { González 10\% Luis Enrique Comparán Sánchez 10\% }\end{array}$ \\
\hline Validación & Carlos Alberto Torres Balcázar 50\% Gaspar López Ocaña 50\% \\
\hline Análisis formal & $\begin{array}{l}\text { Gaspar López Ocaña 50\% Carlos Alberto Torres Balcázar 20\% } \\
\text { Mario José Romellón Cerino 10\% María Berzabé Vázquez } \\
\text { González 10\% Luis Enrique Comparán Sánchez10\% }\end{array}$ \\
\hline Investigación & Carlos Alberto Torres Balcázar 50\% Gaspar López Ocaña 50\% \\
\hline Recursos & Gaspar López Ocaña 100\% \\
\hline Curación de datos & Carlos Alberto Torres Balcázar 50\% Gaspar López Ocaña 50\% \\
\hline $\begin{array}{l}\text { Escritura. Preparación del } \\
\text { borrador original }\end{array}$ & $\begin{array}{l}\text { Gaspar López Ocaña 50\% Carlos Alberto Torres Balcázar 20\% } \\
\text { Mario José Romellón Cerino 10\% María Berzabé Vázquez } \\
\text { González 10\% Luis Enrique Comparán Sánchez 10\% }\end{array}$ \\
\hline Escritura. Revisión y edición & $\begin{array}{l}\text { Gaspar López Ocaña 60\% Carlos Alberto Torres Balcázar 10\% } \\
\text { Mario José Romellón Cerino 10\% María Berzabé Vázquez } \\
\text { González 10\% Luis Enrique Comparán Sánchez 10\% }\end{array}$ \\
\hline Supervisión & $\begin{array}{l}\text { Gaspar López Ocaña 60\% Carlos Alberto Torres Balcázar 10\% } \\
\text { Mario José Romellón Cerino 10\% María Berzabé Vázquez } \\
\text { González 10\% Luis Enrique Comparán Sánchez 10\% }\end{array}$ \\
\hline Administración de proyectos & Gaspar López Ocaña 50\% Carlos Alberto Torres Balcázar 50\% \\
\hline Adquisición de fondos & Gaspar López Ocaña 100\% \\
\hline
\end{tabular}

